\title{
An international comparison analysis of reserve and supply system for emergency medical supplies between China, the United States, Australia, and Canada
}

\author{
Xu Wang ${ }^{1, \S}$, Wenhui $\mathrm{Wu}^{2, \S}$, Peipei Song ${ }^{3}$, Jiangjiang $\mathrm{He}^{1, *}$ \\ ${ }^{1}$ Department of Health Policy Research, Shanghai Health Development Research Center (Shanghai Medical Information Center), Shanghai, China; \\ ${ }^{2}$ Division of Drug Administration, Shanghai Municipal Health Commission, Shanghai, China; \\ ${ }^{3}$ Institute for Global Health Policy Research, Bureau of International Health Cooperation, National Center for Global Health and Medicine, Tokyo, \\ Japan.
}

SUMMARY Coronavirus disease 19 (COVID-19) has become a pandemic around the world. With the explosive growth of confirmed cases, emergency medical supplies are facing global shortage, which restricts the treatment of seriously ill patients and protection of medical staff. Taking China, the United States, Australia, and Canada as examples, this study compares and analyzes the reserve and supply systems of emergency medical supplies and problems exposed in response to the COVID-19 epidemic. Some common problems were found, such as insufficient types and quantities of emergency medical supplies in reserve, insufficient emergency production capacity, and imperfect command mechanism for emergency supplies deployment and transportation. A sound reserve system of emergency medical supplies is the basis and guarantee for dealing with public health emergencies such as major outbreaks. Based on the comparison of systems and practical experience, countries around the world should further improve the reserve and supply system of emergency medical supplies, and improve the coordination and cooperation mechanism for emergency supplies for international public health emergencies, so as to cope with increasingly severe public health emergencies in the context of globalization.

Keywords emergency medical supplies, reserve and supply, COVID-19

\section{Introduction}

Recently, COVID-19 has become a pandemic and affects almost all countries worldwide. As of April 12, 2020, 1,696,588 confirmed COVID-19 cases and 105,952 deaths have been reported around the world (1). Particularly, the United States, Italy and Spain are seriously affected. At the same time, shortage of medical supplies has become a global problem. The world health organization (WHO) has declared that global medical supplies - such as surgical masks, detection reagents, ventilators, et al.- are extremely scarce due to the outbreak of COVID-19 (2), resulting in many patients failing to get timely treatment. In addition, shortage of personal protective equipment endangers medical staff and the epidemic prevention and control situation worldwide, leading to frequent infections of front-line medical staff in some seriously affected countries (3). According to statistical data released by the Italian higher health institute on March 23, the number of confirmed COVID-19 cases among Italian medical staff has risen to
4,824 , accounting for $9 \%$ of the total confirmed cases in Italy (4).

On March 23, 2020, WHO declared that the global outbreak of COVID-19 may affect production and supply of emergency medical supplies and their raw materials, aggravate the shortage of emergency medical supplies and cause unexpected consequences. WHO called for global-level political commitment and coordination, making joint efforts to increase output of emergency medical supplies (5).

This study intends to summarize and analyze the national emergency supplies reserve and supply system of China, the United States, Australia, and Canada, aiming to provide a reference for further improving emergency medical supplies reserve and the supply mechanism for public health emergencies.

\section{Reserve and supply system of emergency medical supplies in China}

In the early stage of the epidemic, the number of 
confirmed COVID-19 cases in China increased rapidly from 571 on January 23 to 74,185 on February 19 (Figure 1A) (6), leading to an explosive increase in demand for medical supplies and a serious shortage of medical supplies. In 1997, China proposed to strengthen the management of the medical reserve (7), required establishment of a central and local two-level medical reserve system and implementation of a system of dynamic reserve and paid redeployment program. It was clarified that the central medical reserve was mainly responsible for storing special medicines and medical devices needed for major disasters, epidemics, major emergencies, and strategic reserves. The local medical reserve was mainly responsible for storing medicines and medical devices needed for prevention and treatment of regional or general disasters, epidemics, emergencies, and local common diseases and frequently-occurring diseases. When it is necessary to make urgent use of the national reserved medicines and medical devices, the local reserve shall be responsible for the supply and the central reserve shall supplement the supply in principle. According to the level and involved region of disasters, epidemics, and emergencies, the order of the medicine reserve use is stipulated. In 1998, the Ministry of Finance of the People's Republic of China issued financial management measures for the national medical reserve fund to ensure its effective use (8). When there are no emergencies such as catastrophic disasters or epidemics, more than $70 \%$ of the medical reserve funds allocated by the state should be stored in physical form in the reserve enterprises. The storage sites are located in the northeast, north, northwest, and middle regions of China, and the modern logistics system ensures timely allocation of medicines.

In 1999, China further promulgated the National Pharmaceutical Reserve Management Measures (9) and clarified that the Ministry of Industry and Information Technology was the main management department of the national medical reserve. The Ministry of Industry and Information Technology is responsible for the coordination of national medical reserve work, organizing and making the annual plan of the central medical reserve, and collaborating with relevant departments to timely adjust the kinds of medicines and medical devices

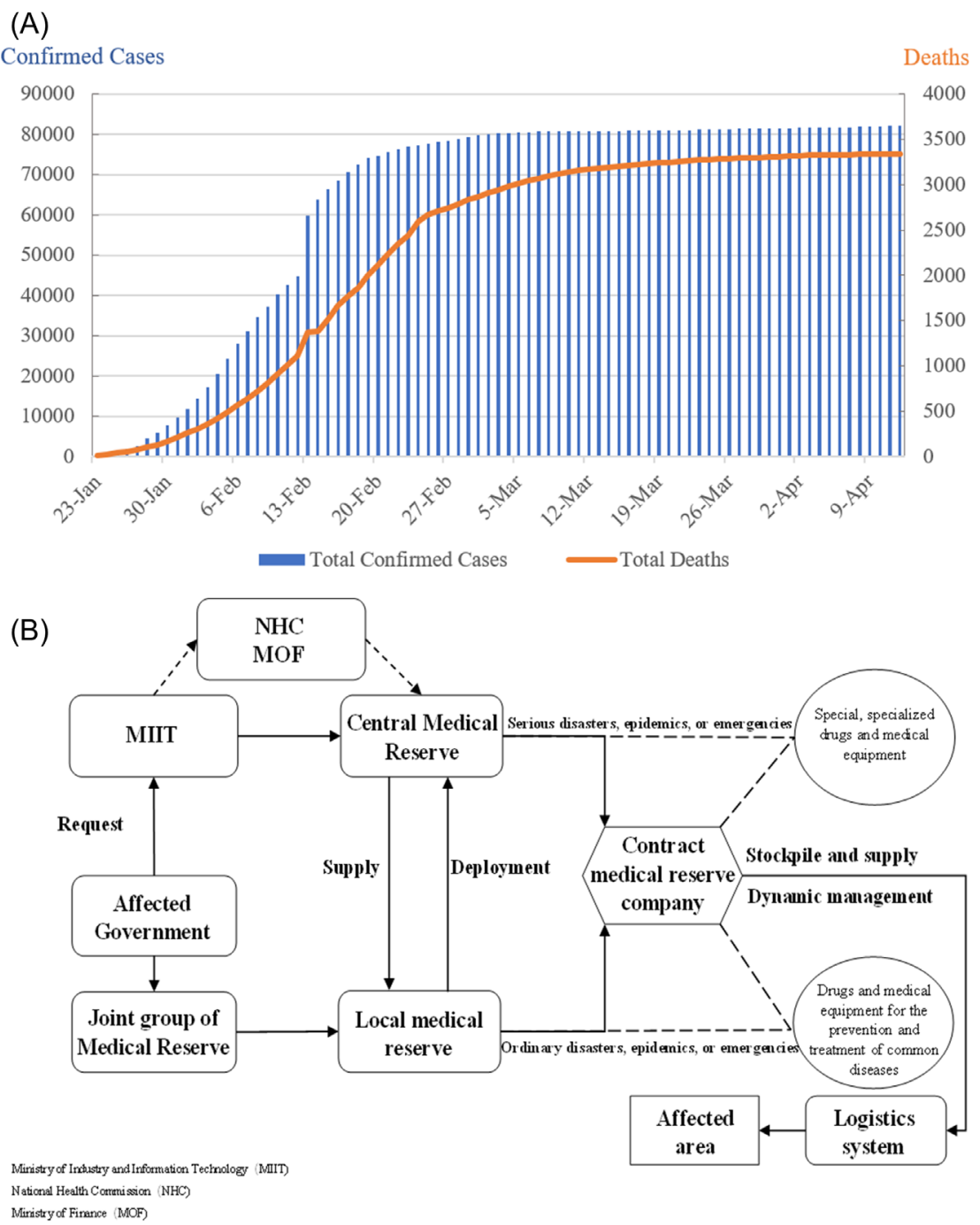

Figure 1. (A) Trends in the number of confirmed COVID-19 cases and deaths in China; (B) Reserve and supply system of emergency medical supplies in China. 
in the central reserve. Enterprises that undertake medical reserves are responsible for implementing the medical reserve plan issued by the medical reserve management department and rotating reserve medicines and medical devices in a timely fashion to ensure the quality of the reserve medicines and medical devices (Figure 1B). Since the Severe Acute Respiratory Syndrome (SARS) broke out in 2003, China officially issued documents such as Regulations on Preparedness and Responses to Emergent Public Health Hazards (10) and further improved the emergency medical reserve and supply system. In 2004, under the unified deployment of the State Council, the National Development and Reform Commission organized the National Medical Reserve Emergency Plan, established the basic system and operation mechanism of emergency management of medical reserves, and strengthened the basic work of emergency management. In 2008, China formulated the (Draft) Catalogue of health emergency personnel and equipment (11), where the types and standards of emergency supplies were clearly stipulated. The reserves mainly include special and conventional reserves types.
The special reserves are aimed at emergencies and epidemics such as anti-terrorism, SARS, AIDS, avian influenza, H1N1 influenza, et al. The special reserves include biological vaccine products, killing drugs, treatment medicines for chemical poisoning, antiviral drugs, etc. The conventional reserves, including medical devices and medicines such as antibiotics, analgesics, and narcotics, are required for general disasters, epidemics, and emergencies $(12,13)$.

\section{Reserve and supply system of emergency medical supplies in the United States}

Since March, the number of confirmed COVID-19 cases in the United States has shown explosive growth. From 62 cases reported on March 1 to 492,881 cases on April 12 , the United States has become the country with the most confirmed cases in the world (Figure 2A) (14). Under these circumstances, the shortage of emergency medical supplies such as masks, detection kits, protective equipment, and ventilators emerge continuously. In 1999, the United States Congress authorized the Department

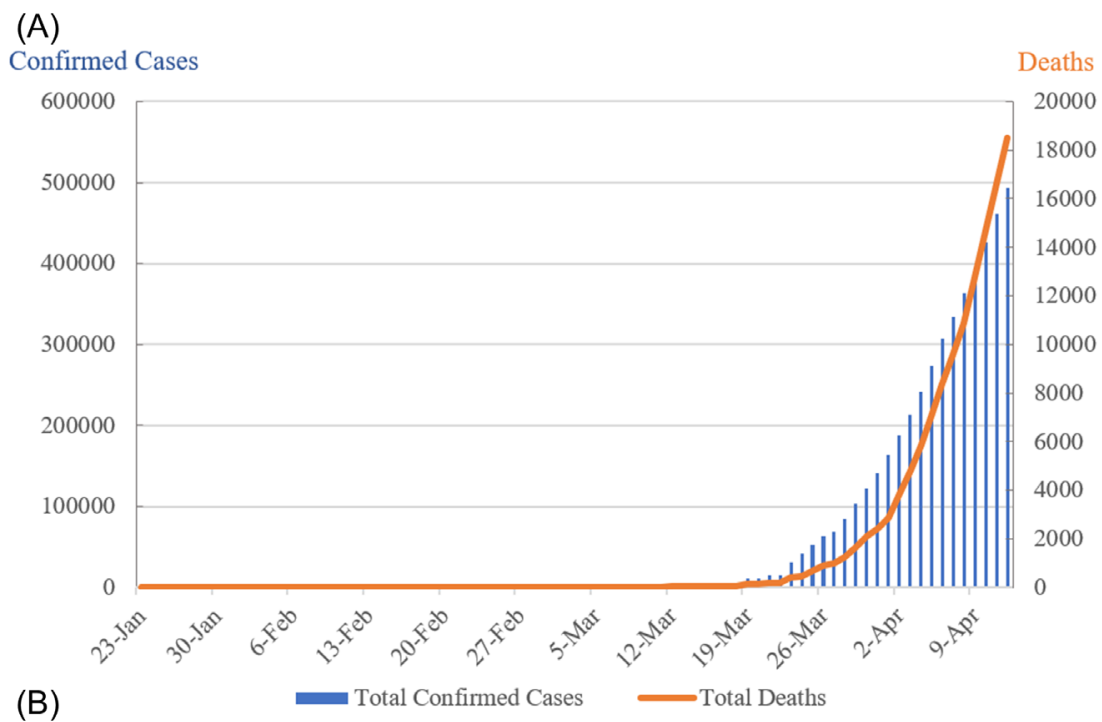

(B)

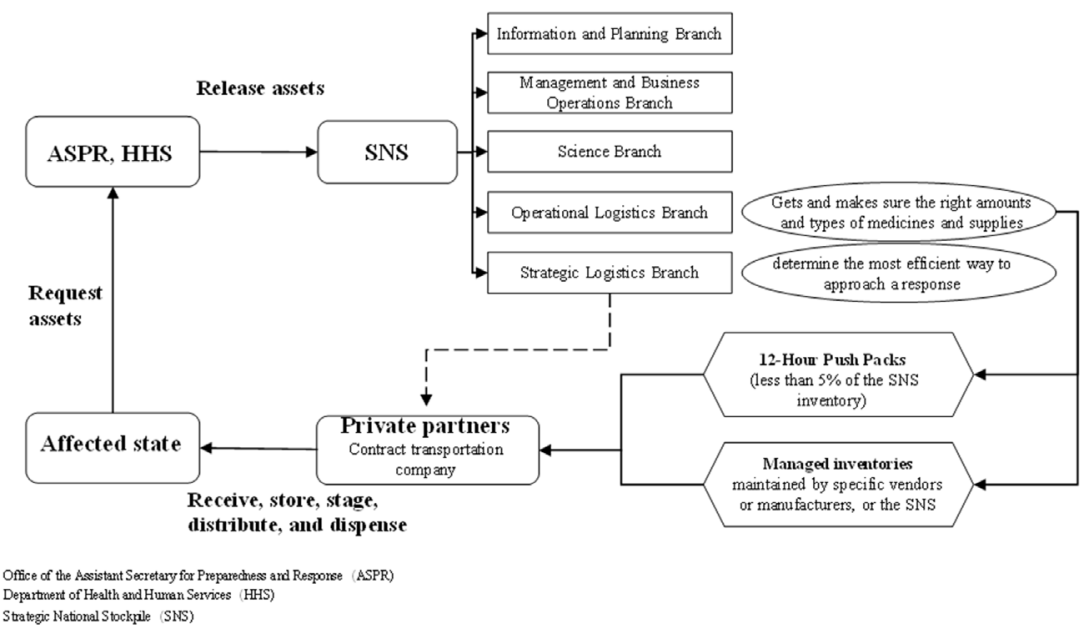

Figure 2. (A) Trends in the number of confirmed COVID-19 cases and deaths in the United States; (B) Reserve and supply system of emergency medical supplies in the United States. 
of Health and Human Services (HHS) and subordinate Centers for Disease Control and Prevention (CDC) to implement the National Pharmaceutical Stockpile (NPS) plan $(15,16)$, aiming to procure medicines and vaccines for storage and deal with the threat of potential biological, chemical and major infectious diseases. In 2003, NPS became the Strategic National Stockpile (SNS). Since 2018, SNS was mainly managed by the Office of the Assistant Secretary for Preparedness and Response (ASPR) under HHS. ASPR is responsible for management, maintenance, and delivery of SNS assets. All states and local governments must formulate plans for receiving, storing, deploying and distributing SNS assets. SNS plans to establish and maintain a national medical supplies repository that can be quickly deployed to emergency sites via the federal government purchasing and storing large amounts of medical supplies in installments and batches. SNS includes information and planning branch, management and business operation branch, operation logistics branch, science branch, and strategic logistics branch. The operation logistics branch is responsible for the procurement and storage of medicines, devices, and vaccines, and makes sure the right amounts and types of medicines and supplies are available to respond to an emergency. The strategic logistics branch is responsible for coordination of relations between public health and other federal agencies and private partners, and coordinates information sharing with states and locals, determining the most efficient way to approach a response (17).

The storage form of emergency medical supplies mainly includes 12 -hour push packages, which are usually stored in 12 locations in the United States; the management inventory maintained by a specific vendor or SNS, which is stored and maintained by the vendor or directly managed by SNS (18). The use of national strategic reserve supplies requires a series of procedures. The requests to call SNS assets before emergencies require solid evidence that there may be biological, chemical, radiological, national public health emergencies, or that emergency events have occurred such as major earthquake, pandemic influenza, smallpox, biology and chemistry, and a serious shortage of medical supplies has appeared. In the above case, the state health department and the governor or designated agent of the affected place can apply directly to HHS for national strategic reserve supplies support, and HHS and other federal agencies quickly evaluate the application and make a decision on whether to allocate. After obtaining approval, the assets provided by SNS will be delivered to any affected states within the United States by the fastest land or air transportation (Figure 2B). At the same time, HHS will regularly inspect the threats and risks of international public health emergencies. On the basis of this, medicines and medical supplies, such as antivirals, ventilators, masks, and gloves, will be added to the SNS reserve (19).

\section{Reserve and supply system of emergency medical supplies in Australia}

In late March, COVID-19 spread rapidly in Australia, with more than 100 cases diagnosed daily (Figure 3A) (14). Since 2002, the Australian Government has officially established the National Medical Stockpile (NMS), aiming to prevent public health emergencies such as epidemic outbreaks and biochemical weapon attacks (20). In June 2006, the Australian Health Ministers' Advisory Council (AHMAC) established the Australian Health Protection Principal Committee (AHPPC) (19). AHPPC is composed of state and regional chief health officers, disaster health experts and other experts in related fields. The purpose is to provide AHMAC with advice on preparedness for public health emergencies and coordinate national emergency response for major incidents. The Health Emergency Management Branch (HEMB) of the Australian Department of Health and Ageing (DHA) Health Protection Office is responsible for the planning and management of NMS, including inventory management, and planning and developing Memoranda of Understanding with states and territories for deployment of the stockpile. The responsibility of HEMB is to provide effective risk assessments, coordinate relevant national health departments to respond to public health emergencies, which may be caused by natural causes or terrorist activities, and to the government's overall emergency management activities. Secondly, HEMB is also responsible for providing strategic advice to AHPC.

NMS is mainly composed of emergency reserves of vaccines, antidotes, highly specialized medicines and protective equipment. The NMS protects Australians from, chemical, biological and radio-nuclear (CBRN) health disasters or pandemic influenza (21). The purpose is to supplement medicines and protective equipment held by state and territory health authorities, ensuring that medical supplies are not in short supply due to public health emergencies. NMS is kept in various strategic locations around Australia, and according to the contract managed by DHA, the inventory is stored in facilities operated by logistics companies. They will be quickly delivered to the places where they are needed if necessary. For security reasons, the exact location and content of these inventories are kept confidentially. All jurisdictions possess a pharmaceutical stockpile separate from the NMS, and all jurisdictions have pre-placed strategic reserves of medicines and personal protective equipment to quickly respond to $\mathrm{CBRN}$ health disasters or pandemic influenza. The NMS inventory includes 42 products and more than 110 million items. The products are mainly related to pandemic influenza prevention (20).

The Australian states and territories have constitutional responsibilities within their responsibility. They are responsible for coordinating and planning for disaster and emergency response, as well as for the 
(A)

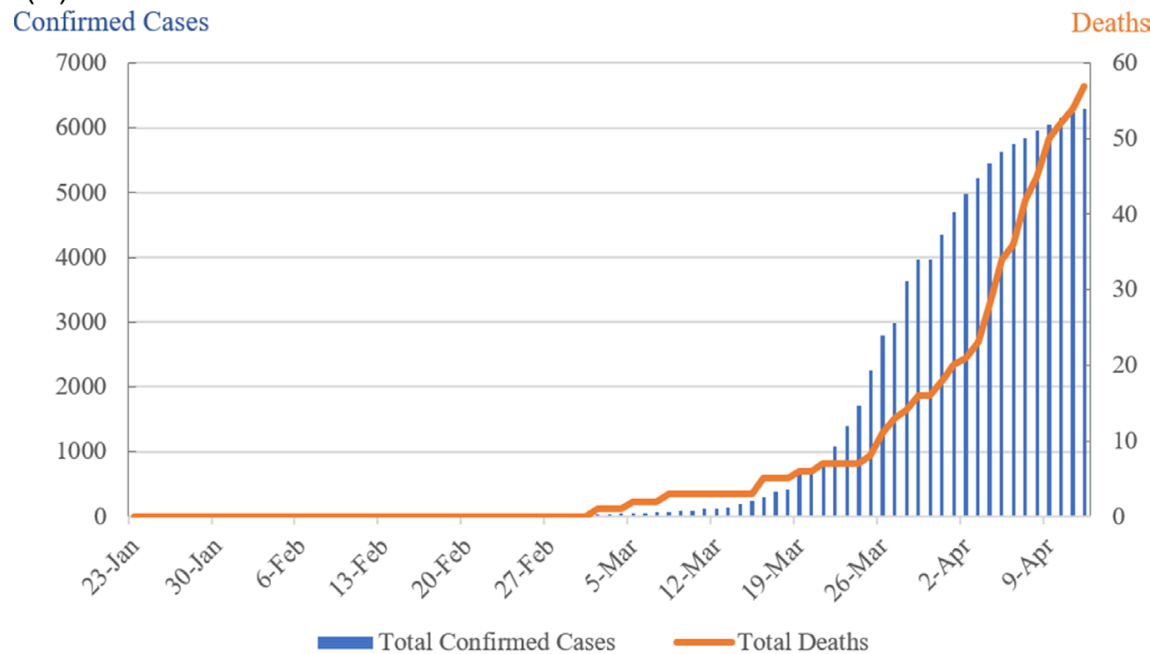

(B)

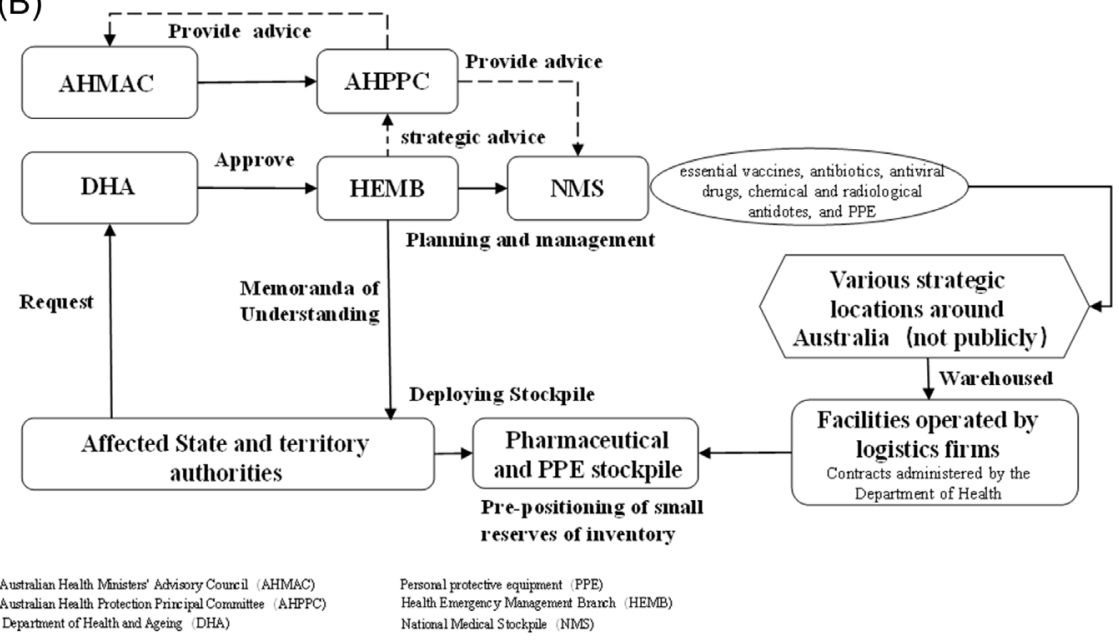

Figure 3. (A) Trends in the number of confirmed COVID-19 cases and deaths in Australia; (B) Reserve and supply system of emergency medical supplies in Australia.

deployment of inventory items in their jurisdictions during national health emergencies. When the total supplies of the affected state or territory cannot reasonably meet the needs of the situation, the state or territory government can seek the assistance of the Government of Australia. The Minister of Health and the Australian Chief Medical Officer have authority for approval to deploy inventory according to the request of state or territory authority. The AHPPC conducts key decision-making consultations on inventory management in consideration of broader health emergency response arrangements (Figure 3B) (19).

After the SARS epidemic, the DHA signed a longterm contract with vaccine manufacturers in 2004 . The purpose is to rapidly develop and supply pandemic vaccines, antiviral agents and Personal Protective Equipment, in response to the next possible pandemic. In 2009, NMS further purchased 21 million doses of H1N1 vaccine in response to the threat of H1N1 influenza, expecting to cover $50 \%$ of the population (19).

\section{Reserve and supply system of emergency medical}

\section{supplies in Canada}

The number of confirmed COVID-19 cases in Canada increased rapidly from 1,739 reported on March 25 to 22,544 on April 12 (Figure 4A) (14). Critical medical supplies are in short supply. In 1952, the Canadian Cabinet authorized the National Health and Welfare Department to reserve basic hygiene products $(22,23)$. Subsequently, the national medical supplies reserve continued to develop, gradually forming National Emergency Strategic Stockpile (NESS), enabling the federal government to respond to changing public health risks in society such as new diseases, natural disasters, and CBRN disasters. In 2004, after the outbreak of SARS, Canada established the Public Health Agency of Canada (PHAC) to manage public health emergencies and improve cooperation within and between jurisdictions (24). The assets of NESS have also been transferred to the newly established Public Health Agency for management and maintenance. The NESS plan is one of the plans of the Office of Emergency Response Services (OERS), Centre for Emergency 
(A)
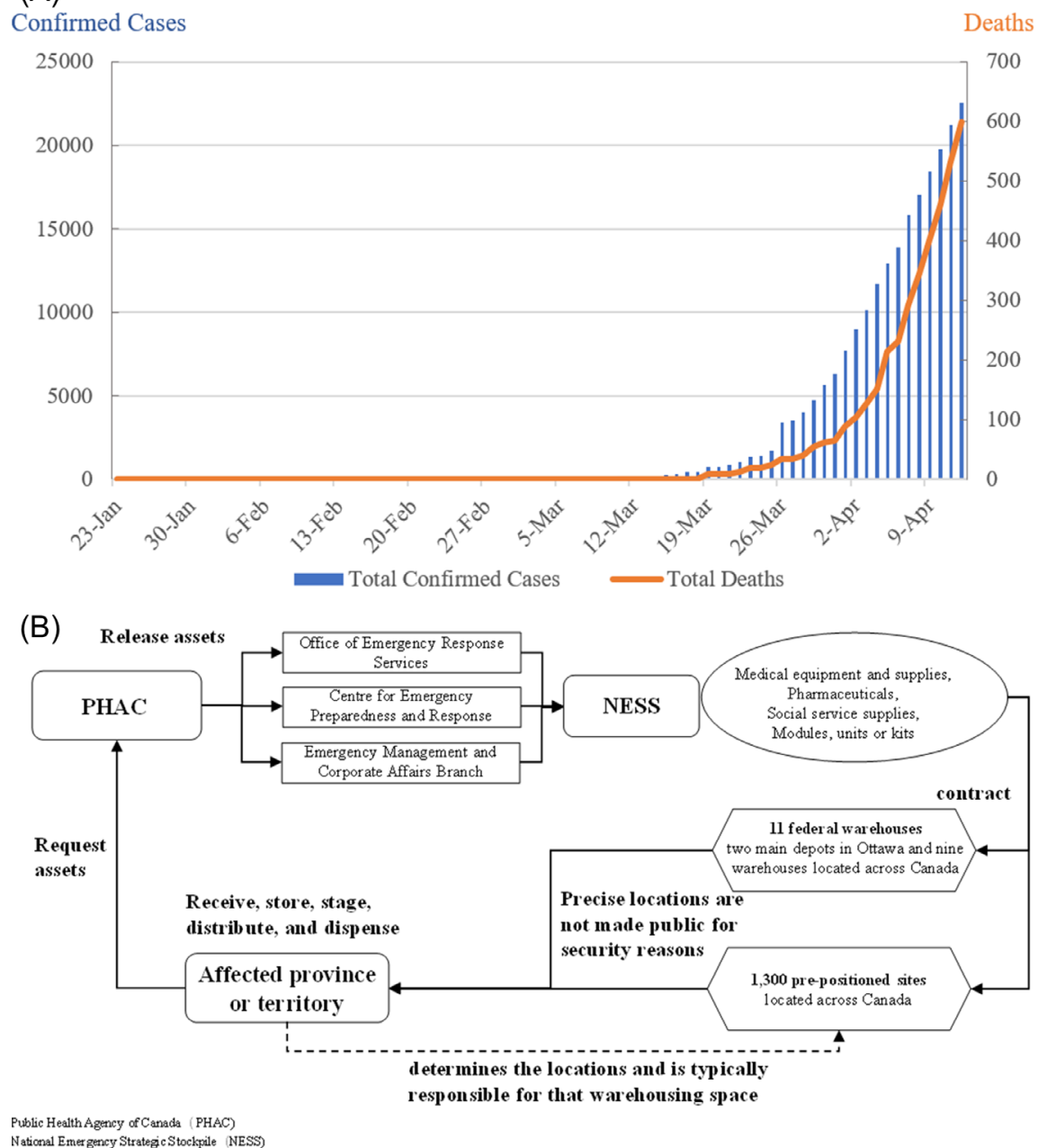

Figure 4. (A) Trends in the number of confirmed COVID-19 cases and deaths in Canada; (B) Reserve and supply system of emergency medical supplies in Canada.

Preparedness and Response, Emergency Management and Corporate Affairs Branch of the PHAC.

The NESS is mainly stored in 11 strategic warehouses leased by PHAC and 1,300 pre-location sites $(25,26)$, including two main warehouses in the National Capital Region (Ottawa) and nine warehouses located across Canada. The specific location of pre-location sites is in the charge of each province or territory. The program indicated that $66 \%$ of supplies deployed are released from the Ottawa depots, $12 \%$ from the other federal warehouses located in the provinces, and $22 \%$ from pre-positioned sites. For safety reasons, the precise location of any warehouse or pre-positioning point will not be disclosed. NESS mainly contains medical equipment and supplies such as ventilators, personal protective equipment, medicines such as antibiotics and antivirals, social service supplies such as beds and generators, and various modules or kits, such as miniclinics and reception center kits. If the local emergency situation overwhelms the available municipal resources, the municipality will contact the provincial or regional emergency management department to obtain more resources. When provinces and territories are unable to provide required resources, they can request for assistance to the PHAC. Emergency supplies can be quickly deployed to any place in the country within 24 hours after a province or region sends a request. The deployment of emergency supplies is coordinated by the provincial or regional health or social services department (Figure 4B). Meanwhile, the assets of NESS have been increasing in response to the pandemic of infectious diseases since the outbreak of SARS. After the H1N1 outbreak in 2009, the scope of supply reserves has been further expanded, including antiviral drugs, ventilators, and related oxygen supply equipment, personal protection equipment, etc. (27).

\section{International comparison of issues and challenges in the reserve and supply system of emergency medical supplies}

Although China, the United States, Australia and Canada have established corresponding reserve and supply systems of emergency medical supplies, the problem of emergency medical reserve and supply is more acute in China and the United States, where the cumulative 
number of confirmed cases is significantly higher than in Australia and Canada.

\subsection{Catalogue}

In 2008, China formulated a reference catalogue of equipment for health emergency teams. However, the national medical reserve catalogue and standards have not been adjusted and updated for many years, which can no longer meet the needs of today's society (12). Some of the medicines and devices, which are necessary for COVID-19 treatment are not in the national medical reserve catalog $(28,29)$. Some commodities cannot be rotated by the enterprises due to outdated varieties. Although the United States, Australia, Canada, and other countries have updated the reserve scope of emergency medical supplies according to major international public health emergencies such as SARS and H1N1, the shortage of medical protection supplies is still a prominent issue in various countries during the fight against the COVID-19 epidemic (30,31). For instance, there are close to 12,700 ventilators in the reserve of the United States, but with the growing severity of the COVID-19 epidemic, the reserves are far from enough to respond to such a serious public health emergency. The state medical institutions are facing a shortage of ventilators (32-34).

\subsection{Procurement}

China issued the reserve catalogue through the medical reserve management department, and the reserve task of the medicines and medical devices was undertaken by the enterprises in accordance with the catalogue. However, the outbreak of COVID-19 quickly spread across the country, and the first-level response was launched at the same time all over the country. Due to the direct requisition of production enterprises by the provinces and municipalities, the lack of information sharing about supplies procurement and provision, coupled with the lack of raw materials, the shortage of employees, and corporate vacations during the Spring Festival, the shortage of emergency medical supplies was exacerbated in some provinces, cities, and regions. In response to this situation, China promptly established a medical supplies support group under the State Council's joint prevention and control of the COVID-19 epidemic. With the Ministry of Industry and Information Technology as the unified coordinating department, the major medical supply production enterprises were mobilized to accelerate the resumption of production, and international procurements were expanded actively through various methods. The shortage of medical emergency supplies has been alleviated to a certain extent (35). The United States mainly purchases medicines and devices that are in urgent need through SNS. However, the national strategic reserve is difficult to deal with during such a serious national epidemic in response to this COVID-19 outbreak. State governments such as Washington DC have stated that the medical supplies received from the federal government are not enough to deal with the epidemic. At the same time, because the federal government has not issued a national emergency supply procurement measure for the COVID-19 epidemic, each state can only procure supplies from various channels on their own $(36,37)$.

\subsection{Reserve}

China requires governments above the county level to "reserve medicines, medical devices and other supplies for the prevention and treatment of infectious diseases" (38). However, at the beginning of the COVID-19 outbreak, it was revealed that the emergency medical supplies reserves in China were insufficient. The reason may be that the emergency medical supplies reserves in China are mainly in the form of physical and capital reserves. The reserve form is relatively simple and the production capacity reserve, information reserve, technical reserve, and other forms are lacking. It is difficult to meet the needs of complex, diverse and unpredictable public health emergencies (29). The main supplies in Australia and Canada are stored in strategic warehouses across the country. Meanwhile, emergency medical supplies are pre-stored in states and regions in the form of pre-positioning sites to quickly respond to CBRN disasters or pandemic infectious diseases. However, during the COVID-19 epidemic prevention and control process, the problem that the emergency medical supply rotation and update system has not been effectively implemented was exposed. For example, Ontario, Canada, as a key area for epidemic prevention and control, the strategic reserve of N95 masks is nearly 55 million. However, more than $80 \%$ of the inventory has expired (39).

\subsection{Delivery and distribution}

China, as the country with the earliest outbreak of COVID-19, in the early stage of response to the epidemic, some key logistics express delivery companies received multi-channel emergency logistics transportation needs from relevant government departments, the military, and local governments. Decentralized demand makes the enterprises feel overwhelmed, coupled with high requirements and insufficient transport capacity during Spring Festival, the enterprises have difficulty in effectively deploying resources and optimizing security. After a large amount of medical supplies from the national emergency allocation, procurement and social donations arrived in Wuhan, they could not be hierarchically classified, managed, and scientifically used. The medical supplies stayed in warehouses for too long and could not be distributed to the urgently 
needed hospitals. Other areas with lighter epidemics have improper use of emergency medical supplies to a certain extent, such as high allocation and waste. The United States has also exposed the problem of uneven distribution of emergency supplies. Currently, some states only receive $10 \%$ of the applied supplies; some states have received more supplies than the number on their applications; and some cities have failed to get any assistance from the state government (40). In addition, inter-regional road conditions and unreasonable seizure issues have also hindered the timely transportation and distribution of emergency medical supplies to a certain extent.

\section{Suggestions for improving the reserve and supply system of emergency medical supplies}

7.1. Formulate a scientific dynamic list of emergency supply reserve requirements

Each emergency has specific needs for emergency medical supplies. By continuous reference, accumulation, and learning, the regularity and characteristics of the actual occurrence of public health emergencies can be grasped. The emergency medical reserve supply lists and standards can be studied and formulated. The scope, type and quantity of emergency medical supplies reserves suitable for each country or region can be determined. The reserve catalogue and standards can be updated according to the practical situation.

\subsection{Improve the storage form of emergency medical supplies}

Owing to the uncertainty of the scope and extent of public health emergencies, supplies can be reserved through physical, capital, production capacity, technology, information, socialized reserves, and other forms according to the storage and use characteristics of emergency supplies. Meanwhile, an emergency medical supplies dynamic rotation updates, supervision and assessment system is suggested to be established, aiming to ensure the quality of emergency medical supplies. It is recommended to build a national (regional) emergency supplies reserve warehouse in areas with convenient transportation and wide radiation range. By the introduction of modern logistics management, the rapid transportation of emergency medical supplies can be achieved.

7.3. Establish a unified dispatch system for emergency medical supplies

It is recommended to establish a coordinated management organization for emergency medical supplies logistics support, aiming to coordinate and solve urgent problems encountered in prevention and control promptly. At the same time, clear operation guidelines and plans should be formulated to ensure the unified operation of emergency supply production, storage, transfer, reception, distribution, transportation, et al. When necessary, logistics enterprises, military technical equipment, personnel and vehicles can be utilized to achieve classified and targeted distribution.

7.4. Strengthen international cooperation in the supply guarantee of emergency medical supplies

The epidemic situation of major infectious diseases often spreads around the world, and the duration is long and the harm is great. It is suggested that the international community establish a higher-level global coordination and cooperation mechanism for public health, led by international organizations to establish a global system for the procurement and supply of emergency medical supplies. At the same time, specialized departments can be established to coordinate the production, procurement, delivery, and distribution of medical supplies in response to major public health emergencies worldwide.

\section{Acknowledgements}

This paper was supported by grants from the China Medical Board Collaborating Project "Establishing Health Policy Transformation Network of China (Project number: CMB-CP 14-190)" (to He Jiangjiang and Wang $\mathrm{Xu})$.

\section{References}

1. World Health Organization. Coronavirus disease 2019 (COVID-19) Situation report - 80. https:// www.who.int/docs/default-source/coronaviruse/ situation-reports/20200409-sitrep-80-covid-19. pdf?sfursn=1b685d64_2 (accessed April 10, 2020).

2. World Health Organization. Coronavirus disease (COVID-19) technical guidance: COVID-19 Critical Items. https://www.who.int/emergencies/diseases/novelcoronavirus-2019/technical-guidance/covid-19-criticalitems (accessed March 30, 2020).

3. World Health Organization. Shortage of personal protective equipment endangering health workers worldwide. https://www.who.int/news-room/detail/0303-2020-shortage-of-personal-protective-equipmentendangering-health-workers-worldwide (accessed March 24, 2020).

4. Xinhuanews. Coronavirus: death toll among doctors in Italy up to 24. http://www.xinhuanet.com/english/ europe/2020-03/24/c_138911288.htm (accessed March 24, 2020). (in Chinese)

5. World Health Organization. WHO Director-General's opening remarks at the media briefing on COVID-19 23 March 2020. https://www.who.int/dg/speeches/detail/ who-director-general-s-opening-remarks-at-the-mediabriefing-on-covid-19---23-march-2020 (accessed March 24, 2020). 
6. National Health Commission of the People's Republic of China. Outbreak Notification. http://www.nhc.gov.cn/ xcs/yqtb/list_gzbd.shtml (accessed April 10, 2020). (in Chinese)

7. Law Yearbook of China. Notice of the State Council on Reforming and Strengthening the Management of Pharmaceutical Stockpile. http://www.pkulaw.cn/fulltext form.aspx?Db=qikan\&gid $=1510046077$ (accessed March 24, 2020). (in Chinese)

8. The State Economic and Trade Commission. Financial Management Measures for National Medicine Reserve Fund. http://www.ccdi.gov.cn/fgk/law_display/4016 (accessed March 24, 2020). (in Chinese)

9. The State Economic and Trade Commission. Provisions for National Pharmaceutical Stockpile. http://www.ccdi. gov.cn/fgk/law_display/3502 (accessed March 24, 2020). (in Chinese)

10. The Central People's Government of the People's Republic of China. National Contingency Plan for Public Health Emergencies. http://www.gov.cn/yjgl/2006-02/26/ content_211654.htm (accessed February 4, 2020). (in Chinese)

11. National Health Commission of the People's Republic of China. (Draft) Catalogue of health emergency personnel and equipment. https://wenku.baidu.com/view/ b8261d33f111f18583d05aa6.html (accessed March 24, 2020). (in Chinese)

12. Cui Y. Perfection of the Research on the State Pharmaceutical Reserve System. Review of Economic Research, 2014; 61: 36-41. (in Chinese)

13. Yu WX, Shi LW, Wang YT. On the Problems of Current Medical Reserve System and Some Policy Proposal for System Reformation in China. China Pharmacy. 2011; 22:780-782. (in Chinese)

14. World Health Organization. Coronavirus disease (COVID-2019) situation reports. https://www.who.int/ emergencies/diseases/novel-coronavirus-2019/situationreports/ (accessed April 10, 2020).

15. U.S. Department of Health \& Human Services. Strategic National Stockpile (SNS). https://chemm.nlm.nih.gov/sns. htm (accessed March 24, 2020).

16. Esbitt D. The Strategic National Stockpile: roles and responsibilities of health care professionals for receiving the stockpile assets. Disaster Manag Response. 2003; 1:68-70.

17. U.S. Department of Health \& Human Services. About the Strategic National Stockpile. https://www.phe.gov/about/ sns/Pages/about.aspx (accessed March 24, 2020).

18. U.S. Department of Health \& Human Services. Stockpile Products. https://www.phe.gov/about/sns/Pages/products. aspx (accessed March 24, 2020).

19. Government of Canada. Appendix G: Evaluation of the National Emergency Stockpile System (NESS) International studies. https://www.canada.ca/en/publichealth/corporate/mandate/about-agency/office-evaluation/ evaluation-reports/evaluation-national-emergencystockpile-system/appendix-g.html (accessed March 24, 2020).

20. Australian National Audit Office (ANAO). Management of the National Medical Stockpile. https://www.anao. gov.au/sites/default/files/AuditReport_2013-2014_53.pdf (accessed March 24, 2020).

21. Australian National Audit Office (ANAO). Australia's Preparedness for a Human Influenza Pandemic. https://www.anao.gov.au/sites/default/files/ANAO
Report 2007-2008 06.pdf (accessed March 24, 2020).

22. Government of Canada. National Emergency Strategic Stockpile. https://www.canada.ca/en/public-health/ services/emergency-preparedness-response/nationalemergency-strategic-stockpile.html (accessed March 24, 2020).

23. Hacon WS. The employment of emergency medical units of the National Medical Stockpile. Can Med Assoc J.1967; 96:185-191.

24. Government of Canada. Canadian Pandemic Influenza Preparedness: Planning Guidance for the Health Sector. https://www.canada.ca/en/public-health/services/fluinfluenza/canadian-pandemic-influenza-preparednessplanning-guidance-health-sector.html (accessed March 24, 2020).

25. Government of Canada. Section 2: Evaluation of the National Emergency Stockpile System (NESS) Background. https://www.canada.ca/en/public-health/ corporate/mandate/about-agency/office-evaluation/ evaluation-reports/evaluation-national-emergencystockpile-system/background-context.html\#background-1 (accessed March 24, 2020)

26. Government of Canada. Appendix A: Evaluation of the National Emergency Stockpile System (NESS) - Lifecycle management. https://www.canada.ca/en/publichealth/corporate/mandate/about-agency/office-evaluation/ evaluation-reports/evaluation-national-emergencystockpile-system/appendix-a.html (accessed March 24, 2020).

27. Government of Canada. Appendix B: Evaluation of the National Emergency Stockpile System (NESS) Technical annex. https://www.canada.ca/en/public-health/ corporate/mandate/about-agency/office-evaluation/ evaluation-reports/evaluation-national-emergencystockpile-system/appendix-b.html (accessed March 24, 2020).

28. China Net. The National Medicine Reserve should be replaced. http://finance.china.com.cn/ roll/20140411/2327951.shtml (accessed March 24, 2020). (in Chinese)

29. Yuan HSB, Huang YM, Fan MS, Shao R. The improvement of the medical reserve form in China. Chinese Journal of Pharmaceuticals. 2018; 49: 869-874. (in Chinese)

30. Kokudo N, Sugiyama H. Call for international cooperation and collaboration to effectively tackle the COVID-19 pandemic. Global Health \& Medicine. 2020; 2:60-62.

31. Villa S, Lombardi A, Mangioni D, Bozzi G, Bandera A, Gori A, Raviglione MC. The COVID-19 pandemic preparedness... or lack thereof: from China to Italy. Global Health \& Medicine. 2020; 2:73-77.

32. ABC NEWS. Hospitals fear shortage of ventilators for virus patients. https://abcnews.go.com/Health/ wireStory/hospitals-fear-shortage-ventilators-viruspatients-69651300 (accessed March 30, 2020).

33. China Daily Global. US hospitals press for ventilators. http://www.chinadaily.com.cn/a/202003/25/ WS5e7ae160a310128217281e32.html (accessed March $30,2020)$.

34. CNN. The COVID-19 ranking system that could decide who gets a ventilator. https://us.cnn.com/videos/ us/2020/04/03/hospital-point-system-griffin-lead-pkg-vpx. cnn/video/playlists/top-news-videos/ (accessed April 4, 2020).

35. Wang X, Zhang X, He JJ. Challenges to the system of 
reserve medical supplies for public health emergencies: reflections on the outbreak of the severe acute respiratory syndrome coronavirus 2 (SARS-CoV-2) epidemic in China. BioSci Trends. 2020; 14:3-8.

36. CNN. Trump administration edits national stockpile website a day after it contradicted Jared Kushner. https:// edition.cnn.com/2020/04/03/politics/stockpile-websiteedited-kushner-claim/index.html (accessed April 4, 2020).

37. CNBC. Cuomo says coronavirus is 'more dangerous' than expected as New York cases jump 14\% overnight to 75,795. https://www.cnbc.com/2020/03/31/gov-cuomosays-coronavirus-is-more-dangerous-than-expected-asnew-york-cases-jump-14percent-overnight-to-75795. html? \& qsearchterm $=$ Cumo $\% 20$ says $\% 20$ coronavirus $\% 20$ is\%20more (accessed April 4, 2020).

38. The Central People's Government of the People's Republic of China. The 2004 Revised Law of the People's Republic of China on the Prevention and Treatment of Infectious Diseases. http://www.gov.cn/gongbao/content/2004/ content_62975.htm (accessed March 25, 2020). (in Chinese)
39. Exclusive: Millions of masks stockpiled in Canada's Ontario expired before coronavirus hit. http://www. yidianzixun.com/article/0OpB8wvI? $=y u n o s \&$ appid $=s 3$ rd_yunos (accessed March 24, 2020). (in Chinese)

40. Guanchacn. How many federal supplies can the US states take? It depends on the relationship between the governor and Trump? https://www.guancha.cn/ internation/2020_04_01_544987.shtml (accessed April 4, 2020). (in Chinese)

Received April 15, 2020; Revised May 6, 2020; Accepted May 8,2020

${ }^{\S}$ These authors contributed equally to this work.

*Address correspondence to:

Jiangjiang He, Shanghai Health Development Research Center (Shanghai Medical Information Center), No.1477 Beijing (W) Road, Jing'an District, Shanghai 200040, China.

E-mail: hejiangjiang@shdrc.org

Released online in J-STAGE as advance publication May 9, 2020. 